\title{
Targeting metastatic cancer from the inside: A new generation of targeted gene delivery vectors enables personalized cancer vaccination in situ
}

\author{
ERLINDA M. GORDON ${ }^{1,2}$, JOHN P. LEVY ${ }^{1}$, REBECCA A. REED ${ }^{1}$, W. NINA PETCHPUD ${ }^{1}$, \\ LIQIONG LIU ${ }^{1,2}$, CARLAN B. WENDLER ${ }^{2}$ and FREDERICK L. HALL ${ }^{1}$ \\ ${ }^{1}$ Oncology Research Unit, Epeius Biotechnologies Corporation, San Marino, CA 91108; ${ }^{2}$ Department of Pediatrics, \\ Keck School of Medicine, University of Southern California, Los Angeles, CA 90033, USA
}

Received June 30, 2008; Accepted July 24, 2008

DOI: 10.3892/ijo_00000052

\begin{abstract}
The advent of pathotropic (disease-seeking) targeting technologies, combined with advanced gene delivery vectors, provides a unique opportunity for the systemic delivery of immunomodulatory cytokine genes to remote sites of cancer metastasis. When injected intravenously, such pathotropic nanoparticles seek out and accumulate selectively at sites of tumor invasion and neo-angiogenesis, resulting in enhanced gene delivery, and thus cytokine production, within the tumor nodules. Used in conjunction with a primary tumoricidal agent (e.g., Rexin-G) that exposes tumor neoantigens, the tumortargeted immunotherapy vector is intended to promote the recruitment and activation of host immune cells into the metastastic site(s), thereby initiating cancer immunization in situ. In this study, we examine the feasibility of cytokine gene delivery to cancerous lesions in vivo using intravenously administered pathotropically targeted nanoparticles bearing the gene encoding granulocyte/macrophage colony-stimulating factor (GM-CSF; i.e., Reximmune-C). In vitro, transduction of target cancer cells with Reximmune-C resulted in the quantitative production of bioactive and immunoreactive GM-CSF protein. In tumor-bearing nude mice, intravenous infusions of Reximmune-C-induced GM-CSF production by transduced cancer cells and paracrine secretion of the cytokine within the tumor nodules, which promoted the recruitment of host mononuclear cells, including $\mathrm{CD} 40^{+} \mathrm{B}$ cells and $\mathrm{CD} 86^{+}$ dendritic cells, into the tumors. With the first proofs of principle established in preclinical studies, we generated an optimized vector configuration for use in advanced clinical trial designs, and extended the feasibility studies to the clinic.
\end{abstract}

Correspondence to: Dr Erlinda M. Gordon, Epeius Biotechnologies Corporation, 475 Huntington Drive, San Marino, CA 91108, USA

E-mail: emgordon@epeiusbiotech.com

Key words: gene transfer, gene therapy, cytokines, granulocyte/ macrophage colony-stimulating factor, pathotropic nanoparticles, nanomedicine
Targeted delivery and localized expression of the GM-CSF transgene was confirmed in a patient with metastatic cancer, as was the recruitment of significant tumor-infiltrating lymphocytes (TILs). Taken together, these studies provide the first demonstrations of cytokine gene delivery to cancerous lesions following intravenous administration and extend the applications of cancer immunization in vivo.

\section{Introduction}

Immune modulation, in conjunction with tumor antigen presentation, represents a promising approach for optimizing the efficacy of cancer gene therapy protocols. In tumor vaccination strategies, cytokines such as granulocyte/macrophage colonystimulating factor (GM-CSF) are employed to recruit antigenpresenting cells, including dendritic cells and macrophages, which result in the activation of tumor-infiltrating $\mathrm{B}$ and $\mathrm{T}$ lymphocytes against proteins expressed by cancer cells $(1,2)$. GM-CSF, in particular, is known to induce the activation, migration, proliferation, and differentiation of a variety of immunologically active cell populations, thereby facilitating the development of both humoral- and cellular-mediated immunity (3-5). One promising vaccine approach involves the insertion of the GM-CSF gene into autologous cancer cells which are then irradiated and used for personalized immunization $(6,7)$. These genetically engineered tumor cells produce the GM-CSF protein within the local environment of the cells, thereby activating the patients' own immune system to recognize these tumor cells and, eventually, to eradicate the cancer at other metastatic sites. Whether delivered as genetically engineered tumor cells or as a soluble GM-CSF protein, the cytokine must be present within the same compartment as the antigenic components (8). Indeed, the establishment of specific and long lasting antitumor immunity following vaccination with GM-CSF-transduced tumor cells requires the simultaneous presence of GM-CSF and tumor antigens at the vaccination site (9). However, in spite of the therapeutic potential demonstrated in animal models and early-phase clinical trials, the clinical development of these promising protocols has been limited by difficulties relating to the establishment of autologous tumor cell cultures (10) and/or the performance of individualized gene transfer procedures 
ex vivo (11). Moreover, it has been reported that 'live' GM-CSF-secreting tumor cell vaccines are considerably more effective than irradiated GM-CSF-secreting tumor cell vaccines in generating systemic antitumor immunity (12). Alternatively, localized delivery of GM-CSF by direct intratumoral injection, as well as paracrine secretion by genetically engineered cells, has been shown to be more effective in upregulating lymph node sensitization when compared to systemic administration of the recombinant protein $(13,14)$. Unfortunately, the majority of primary and metastatic lesions are not readily accessible for direct intratumoral injection, thus opportunities for effective anti-cancer vaccination remained out of reach.

An obvious approach to raising cytokine levels selectively within a cancerous lesion is the prospect of selective gene delivery, and a large number of gene delivery systems, or vectors, have been developed for such purposes $(15,16)$. In this regard, the retroviral particle, rendered replicationincompetent by strategic molecular engineering, exhibits a set of virtues and inherent limitations that are particularly amenable to anti-cancer applications $(10,16-18)$. Not only are these membrane-enveloped viral particles durable in terms of transit within the systemic circulation and efficient in terms of their gene delivery function, they are virtually stealth in terms of the immune system, thereby enabling repeated infusions to be administered without eliciting untoward and/or immediately inactivating immune responses $(19,20)$. Retroviral particles based on the murine leukemic virus (MLV) exhibit a unique and purposeful limitation of infectivity that is restricted to dividing cells only, which serves to limit gene delivery to proliferative cancer cells and the proliferative vascular cells of a tumor's blood supply, thus effectively sparing normal, non-dividing cells (21). In addition to these critical properties, the small size of these retroviral particles $(100 \mathrm{~nm})$ enhances the biodistribution and the histological penetrance, thus conducting the much-anticipated field of nanotechnology across the threshold of history and into the practical realm of medical delivery $(16,22)$.

In this study, we will briefly review the bioengineering principles employed in the progressive evolution of the MLV retroviral vector, with an aim toward improving both the safety and the efficacy of this important gene delivery platform, as well as the efficiencies and economies of its biopharmaceutical production. While this platform has been employed as the vector of choice in a large number of clinical trials $(23,24)$, its recorded clinical serviceability left much to be desired. While the deconstruction of its molecular components from an infectious agent to a non-replicative gene delivery vehicle, or vector, served to improve the safety of the system enormously, there remained a significant probability of inadvertent recombination (RCR) in these vector constructs (25) and the prospective titers, or potency, of the resulting nanomedicines were severely compromised. Many engineering attempts have been made to target the MLV vector, to restrict and/or to focus gene delivery to specific cells or tissues; however, such attempts at retargeting were generally disappointing (26-28), with few exceptions (16,29-31). A further issue concerns vector integration into chromosomes, and additional safety considerations that arise when the intention is not to destroy the target cell immediately, but to direct its activity toward prolonged therapeutic gene expression - a topic that is further developed in the discussion section of this study.

With the advent of pathotropic (disease-seeking) nanobiotechnology, and the development of tumor-targeted gene vectors for cancer therapy, we were able to demonstrate the efficiency of the targeting technology in general and the efficacy of the tumoricidal anti-cancer agent Rexin-G following intravenous administration in a series of detailed preclinical studies $(32,33)$, followed by a series of clinical trials that confirmed the safety, the efficiency, and the validity of the tumor-targeting platform for specified clinical applications (34-36). Remarkably, Rexin-G remains the first and so far only targeted gene delivery vector that has been successfully tested in the clinic $(16,35)$. In this study, we report on: i) the new state-of-the-art in retroviral vector design engineering and ii) the potential for clinical applications of this applied nanobiotechnology in the form of personalized cancer vaccination. Moreover, we present a promising new approach for the treatment of metastatic cancer by demonstrating the feasibility of deploying a pathotropically targeted and intravenously injectable vector, designated Reximmune-C (36), to efficiently deliver a cytokine gene into remote tumors in vivo for the purpose of promoting a cancer vaccination in situ.

\section{Materials and methods}

Cells and cell culture conditions. NIH3T3 cells, A375 human melanoma cells, HT1080 human fibrosarcoma cells, and MiaPaca2 human undifferentiated pancreatic cancer cells were obtained from ATCC (Rockville, MD, USA). The 293T human kidney cell line transformed with SV40 large T antigen is maintained by Epeius Biotechnologies Corp. (San Marino, CA) as a certified master cell bank. All cell lines were cultured in Dulbecco's modified Eagle's medium supplemented with $10 \%$ fetal bovine serum.

Molecular engineering of the GM-CSF retroviral expression vectors. The described version of a 3 rd generation retroviral expression vector (pREX II) was created by engineering a multiple cloning site (MSC) into the G1XSvNa vector (Genetic Therapy, Inc.) to produce $\mathrm{G} 1(\mathrm{MCS}) \mathrm{SvNa}$, which is then subjected to KpnI digestion followed by fusion of the KpnI fragment with the linearized pRV109 vector (37). The resulting pREX II retroviral expression vector is driven externally by the strong CMV promoter and internally (packaged components) by a hybrid MSV/MLV promoter at the 5' LTR and a standard MLV LTR at the $3^{\prime}$ end. Bearing the strong CMV promoter and an SV40 ori, this plasmid is suitable for relatively hightiter vector production in $293 \mathrm{~T}$ cells prepared by transient transfection protocols $(33,34)$. The $0.44 \mathrm{~kb}$ cDNA encoding a GM-CSF factor, GenBank accession number NM 000758, flanked by PCR-derived restriction sites was cloned into the unique NotI (5') and XhoI (3') cloning sites of the pREX II vector. The 4th Generation (C-REX) and 5th Generation (Uber-Rex) retroviral vectors were developed specifically for clinical use by Epeius Biotechnologies Corp. to eliminate all extraneous sequences that would otherwise be introduced by plasmid fusions and to incorporate greater efficiencies in vector packaging and production, while virtually eliminating 
the incidence of inadvertent recombination. The advanced GM-CSF construct in Uber-REX (Reximmune-C-TNT) carries an additional gene, herpes simplex thymidine kinase (HSV-Tk), which serves as an additional safety feature ('suicide gene') by engendering cellular sensitivity to destruction by ganciclovir (GCV) or acyclovir (ACV).

Production of pathotropic vectors bearing the GM-CSF gene. High titer retroviral vectors were generated utilizing a transient three plasmid co-transfection system in which the packaging components gag-pol, the wild-type 4070A amphotropic (CAE) env or a chimeric MLV-based env construct bearing an auxiliary extracellular matrix targeting domain, and a retroviral packaging/expression vector bearing the respective GM-CSF construct were placed on separate plasmids, each containing a CMV promoter and an SV40 origin of replication $(33,36)$. The tumor surveillance function of the pathology-targeted (pathotropic, disease-seeking) env protein results from the insertion of a matrix-binding peptide, derived from von Willebrand coagulation factor, into the primary structure of the MLV 4070A amphotropic envelope protein $(\mathrm{CAE}, 30)$. The resultant pathotropic vector exhibits a high-efficiency tumor-targeting feature, i.e., the ability to seek out and accumulate upon the exposed collagenous interfaces within the cancerous lesions (32-36). The resulting vectors are referred to as Mx-GM-CSF (or Reximmune-C), Mx-GM-CSF-Tk (Reximmune-C-TNT), CAE-GM-CSF (nontargeted control), and Mx-Null (targeted empty vector), to indicate the envelope arrayed on, and gene(s) encoded in, each vector.

Determination of viral titers. The infectious titers of retroviral vectors in murine NIH3T3 cells were determined as previously described, based on expression of the B-galactosidase or neomycin phosphotransferase resistance, neo ${ }^{\mathrm{r}}$, gene (38). Viral titers are expressed as the number of nuclear $\beta$-galactosidase expressing colonies or G418 resistant colony forming units $(\mathrm{CFU}) / \mathrm{ml}$; however, the titer of Reximmune-C-TNT in the advanced Uber-REX vector system was determined as HATresistant $\mathrm{CFU} / \mathrm{ml}$. Viral titers ranged from $1 \times 10^{7} \mathrm{CFU} / \mathrm{ml}$ to $1 \times 10^{10}$, depending on the inherent performance of the individual plasmids utilized, the co-transfection parameters, and the final bioprocessing steps employed for the production of clinical-grade vectors.

GM-CSF production in transduced cell cultures. To assess the production and secretion of GM-CSF, immunohistochemical staining of transduced cells was conducted using a polyclonal goat antibody raised against a peptide, N19, mapping at the amino terminus of human GM-CSF (Santa Cruz Biotechnology, Inc., Santa Cruz, CA, USA). Moreover, human GM-CSF production was measured in culture medium collected over $48 \mathrm{~h}$ in Reximmune-C transduced NIH3T3 cells and plasmidtransfected 293T producer cell cultures using commercially available ELISA kits supplied by R\&D Systems (Minneapolis, MN, USA). The production and secretion of GM-CSF in cultured cells was measured as concentration in $\mathrm{pg} / \mathrm{ml}$ of culture medium and expressed as $\mu \mathrm{g} / 10^{6}$ cells $/ 24 \mathrm{~h}$. Bioactivity of the secreted GM-CSF protein was confirmed by cell proliferation assays in TF-1 human leukemic cells (39).
In vivo gene transfer studies in mice were conducted in compliance with a protocol approved by the University of Southern California Institution Animal Care and Use Committee. To evaluate the efficiency of targeted gene delivery based on the enforced expression of the GM-CSF transgene in vivo, subcutaneous tumor xenografts were established in $\sim 25 \mathrm{gm}$ athymic nu/nu mice by subcutaneous implantation of $1 \times 10^{7}$ MiaPaca2 human pancreatic cancer cells. When the tumors reached a size of $\sim 20 \mathrm{~mm}^{3}, 200 \mu \mathrm{l}$ of either the Reximmune-C vector, a non-targeted GM-CSF-expressing vector (CAE-GM-CSF), a targeted but empty vector (Mx-null), or phosphate-buffered saline (PBS, pH 7.4), was injected directly into the tail vein each day for a total of 10 days (2x10 $10^{6} \mathrm{CFU} /$ dose; cumulative dose: $2 \times 10^{7} \mathrm{CFU}$ for each vector). The mice were sacrificed by cervical dislocation one day after completion of the treatment cycle. Initial studies of Reximmune-C in human cancer patients were performed under Phase I safety protocols approved by the Philippine BFAD (36) and Asian Hospital and Medical Center's Institutional Review Board. Surgical specimens obtained following treatment with Reximmune-C were fixed in formalin and embedded in paraffin for histological and immunohistochemical analysis.

Immunostaining for human GM-CSF protein in tumor tissues. For detection of the human GM-CSF expression in subcutaneous tumors, tumor tissues harvested at the end of the experiment were fixed in $10 \%$ formalin. Immunohistochemical staining for human GM-CSF was conducted in formalin-fixed tissue sections after antigen retrieval, using an affinity-purified goat polyclonal antibody raised against a peptide mapping at the amino terminus of human GM-CSF (N-19) supplied by Santa Cruz Biotechnology, Inc. After counterstaining with methyl green, the slides were examined for the presence of brownish-red immunostaining material indicating presence of the GM-CSF transgene in tumor sections. The efficiency of gene delivery (expressed as percentage) is determined by counting the number of GM-CSF-secreting cells (based on cytoplasmic GM-CSF immunoreactivity) in three high power fields per tumor nodule, divided by the total number of cells $\mathrm{x} 100$.

Histochemical and immunohistochemical analysis of tumorinfiltrating host mononuclear cells in tumor nodules. Histologic examination of hematoxylin-eosin stained tissue sections of vector-treated tumor-bearing mice were conducted using light microscopy. Purified rat monoclonal anti-mouse CD40 (Catalog \#09661D) and CD86 (B7-2; Catalog \#09271D) antibodies were supplied by PharMingen (USA). Immunostaining for $\mathrm{CD} 40^{+} \mathrm{B}$ cells and $\mathrm{CD} 86^{+}$dendritic cells in acetone-fixed frozen sections of tumor nodules was conducted using methods described previously (32). Immunohistochemical staining of GM-CSF expression in clinical specimens was performed by Dr Xinhai An, at John's Hopkins University, Baltimore, MD; histochemical staining for immunological cell determinants was conducted by Pathology Inc. (El Monte, CA).

Vector toxicity studies. To evaluate potential systemic toxicity, serum GM-CSF, serum chemistry levels and complete blood counts were measured in nude mice that received Reximmune-C 


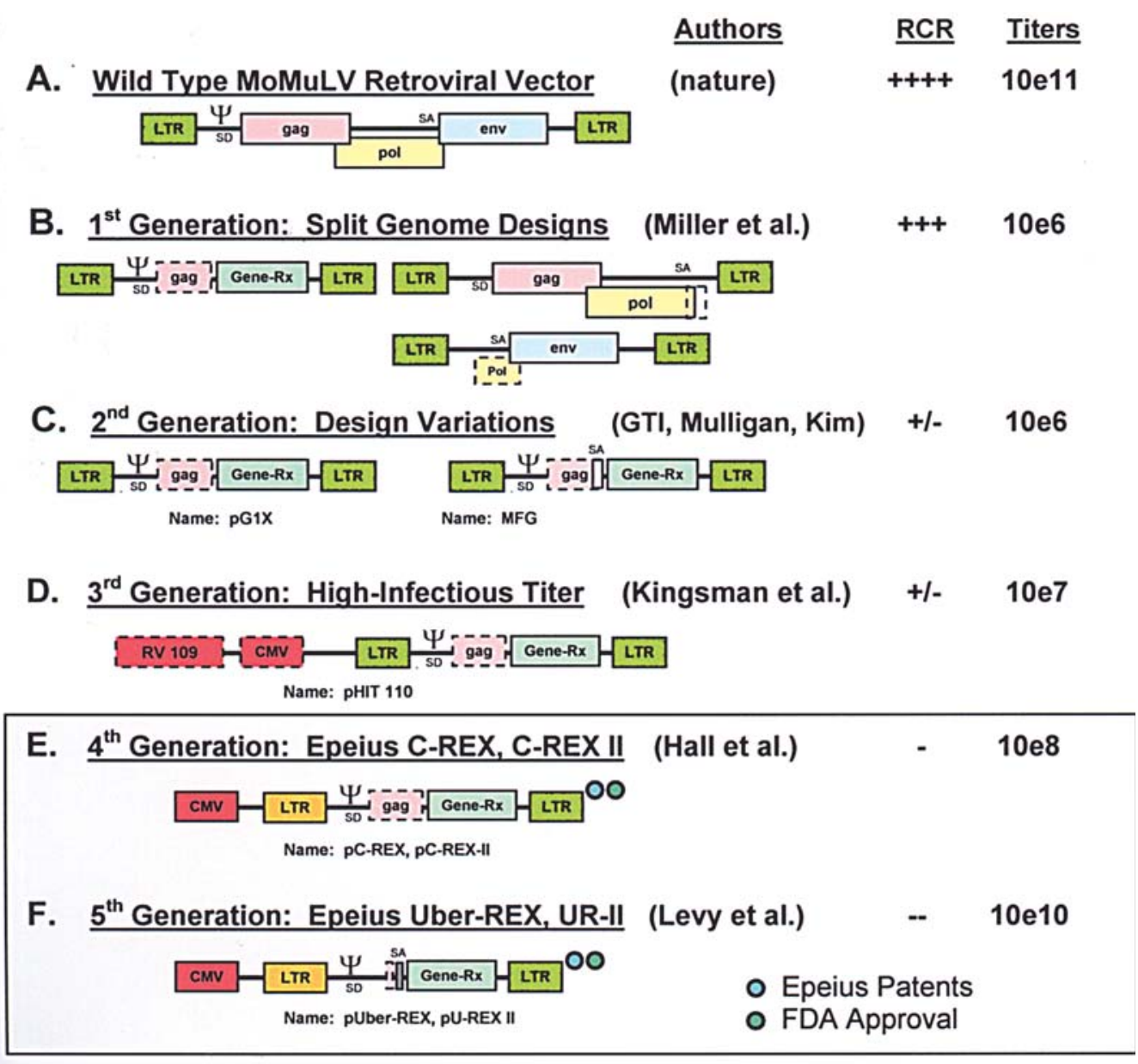

Figure 1. Progressive evolution of retroviral vectors for therapeutic gene delivery. Retroviral vectors for clinical gene therapy initially derived from the wild-type C-type Moloney murine leukemia virus (A), with its structural (gag), enzymatic (pol), and cell-recognition (env) genes gave rise to the Split Genome designs (B) and its Variants (C), which placed the requisite genetic components stably in producer cells while the therapeutic gene, with its integral promoter (LTR) and packaging sequence $(\Psi)$, was placed on a separate plasmid. Subsequent generations of vectors (D) boosted plasmid performance, titers, and fidelity of the vector systems, replacing stable producer cells with transient co-transfection protocols, followed by significant genetic improvements in clinical designs (E, F) that focused on vector production, gene expression, and safety considerations. See text for specific references.

or PBS intravenously for 10 days. Likewise, blood chemistries and GM-GSF levels in patient serum were evaluated following the systemic administration of Reximmune-C.

\section{Results}

Progressive development of retroviral expression vectors for clinical applications. Moloney murine leukemia virus (MoMLV) is an RNA member of the mammalian C type Retrovirus Genera. It is composed of three main gene cassettes: gag (structural), pol (enzymatic), and envelope (cell recognition and entry). The gag gene is further subdivided into the structural genes encoding matrix (MA), capsid (CA) and nucleocapsid (NC), while the enzymatic pol gene is subdivided into three genes encoding protease (PR), reverse transcriptase (RT) and integrase (IN). The wild-type configuration of these gene cassettes is bounded by long-terminal repeat (LTR) sequences, that functions in gene transcription and as a template for replication and integration functions (Fig. 1A). Just downstream of the 5' LTR is a non-coding packaging sequence $(\Psi)$, which is used to load the viral RNA genome into the structural icosohedral capsule of the retroviral particle. The 1st Generation, or split genome design, retroviral vectors developed for clinical gene therapy (40) placed a therapeutic transgene (Gene-Rx) on one plasmid, which contained the $\Psi$ packaging sequence, while the gag-pol and envelope genes were not 'packaged,' as they were intended for use in combination with murine retroviral packaging cell lines. However, vector production was compromised and recombination events leading to the inadvertent production of infectious recombinant retrovirus (RCR) were common (Fig. 1B). Several 2nd Generation designs focused on improving the primary gene transfer plasmids (packaged transgene) by modifying either the LTR promoter sequences or the intrinsic RNA splicing mechanisms $(41,42)$, yet these designs still relied on packaging cell lines for vector production (Fig. 1C).

The 3rd Generation vector designs (Fig. 1D) were developed to improve vector titers and eliminate problematic producer cells by creating plasmid fusions that placed strong exogenous promoters upstream of the 'packaged' retroviral elements (37), and by incorporating SV40 origins of replication into the plasmid backbones, which raised vector titers while replacing stable packaging cell lines with transient cotransfection of the three separate plasmids/gene cassettes in human cell lines containing the SV40 large-T antigen (37). Further advances in vector design led to the 4th Generation 
FDA-approved clinical design (Epeius C-Rex, Fig. 1E) which eliminated cumbersome elements of previous plasmid fusions and placed minimal promoter sequences in an optimal configuration for high performance, thereby yielding appreciably higher titers $(35,43)$. While the performance of these progressively improved 3rd, and 4th Generation retroviral vectors have not generated any detectable RCR vector production in the absence of problematic murine producer cell lines, all of these modern designs retained significant overlaps in homologous sequences that, however unlikely, could possibly recombine in a series of three independent events (42). Thus, the problem of a so-called triple-crossover event that could theoretically generate RCR still loomed over large-scale vector production, necessitating the development of a furtherrefined 5th Generation vector design by Levy et al, of Epeius Biotechnologies (Fig. 1F). Virtually eliminating overlapping sequences, while generating ultra-high vector titers $\left(1 \times 10^{10}\right)$ and retaining the optimized functional elements for efficient packaging, splicing, and gene expression, the 5th Generation Uber-Rex series of vectors represents the current state-of-theart in clinical vector design.

Characterization of GM-CSF transgene expression in cultured cells. Gene transfer studies performed in vitro showed that human GM-CSF was highly expressed in and secreted by both human 293T producer cell and murine NIH3T3 cell cultures. At an MOI of 100, immunoreactive human GM-CSF was noted in $>75 \%$ of plasmid-transfected $293 \mathrm{~T}$ cells and 40 $50 \%$ of vector-transduced NIH3T3 cells ( $n=3$ each group), with human cell lines generally displaying higher levels of infectivity. For Reximmune-C in C-Rex vectors, GM-CSF production was $\sim 100 \mathrm{ng} / 10^{6}$ cells $/ 24 \mathrm{~h}$ in plasmid-transfected $293 \mathrm{~T}$ cell cultures, and $30 \mathrm{ng} / 10^{6}$ cells $/ 24 \mathrm{~h}$ in transduced NIH3T3 cell cultures (Fig. 2), as determined by dilution of the cell culture supernatants and comparison with a purified human GM-CSF standard. Under these standardized conditions, the Uber-Rex vector bearing both the GM-CSF gene and the HSVtk gene (i.e., Reximmune-C-TNT) yielded an average productivity of $50 \mathrm{ng} / 10^{6}$ cells $/ 24 \mathrm{~h}$ (human fibroblastic HT1080 cells), and the bioactivity of the secreted GM-CSF protein was confirmed by bioassay. As shown in Fig. 2C, the addition of either gancylovir (GCV) or acyclovir (ACV) to the culture medium of transduced A375 human melanoma cells resulted in a dose-dependent elimination of the cells with an $\mathrm{IC}_{50}$ of $0.03 \mu \mathrm{m}$ for $\mathrm{GCV}$ and $3.0 \mu \mathrm{m}$ for $\mathrm{ACV}$, respectively.

Pathotropic targeting, GM-CSF expression, and immune modulation in tumor xenografts. We previously reported on the high level transduction (35-50\%) of human tumor cancer xenografts in mice following intravenous infusion of matrixtargeted vectors bearing discernable marker genes $(32,33)$. As shown in Fig. 3, the vector accumulates rapidly in tumorous tissues within minutes of infusion into the general circulation, spreading into the interstices of the tumor nodule and transducing resident tumor cells with high efficiency. As seen in Fig. 3C, this physiological 'surveillance' property of the targeted vector is entirely dependent on the gain-of-function provided by the tumor-targeting moiety. Consistent with the high levels of cell transduction observed within the tumor nodules, immunohistochemical analysis revealed high-level

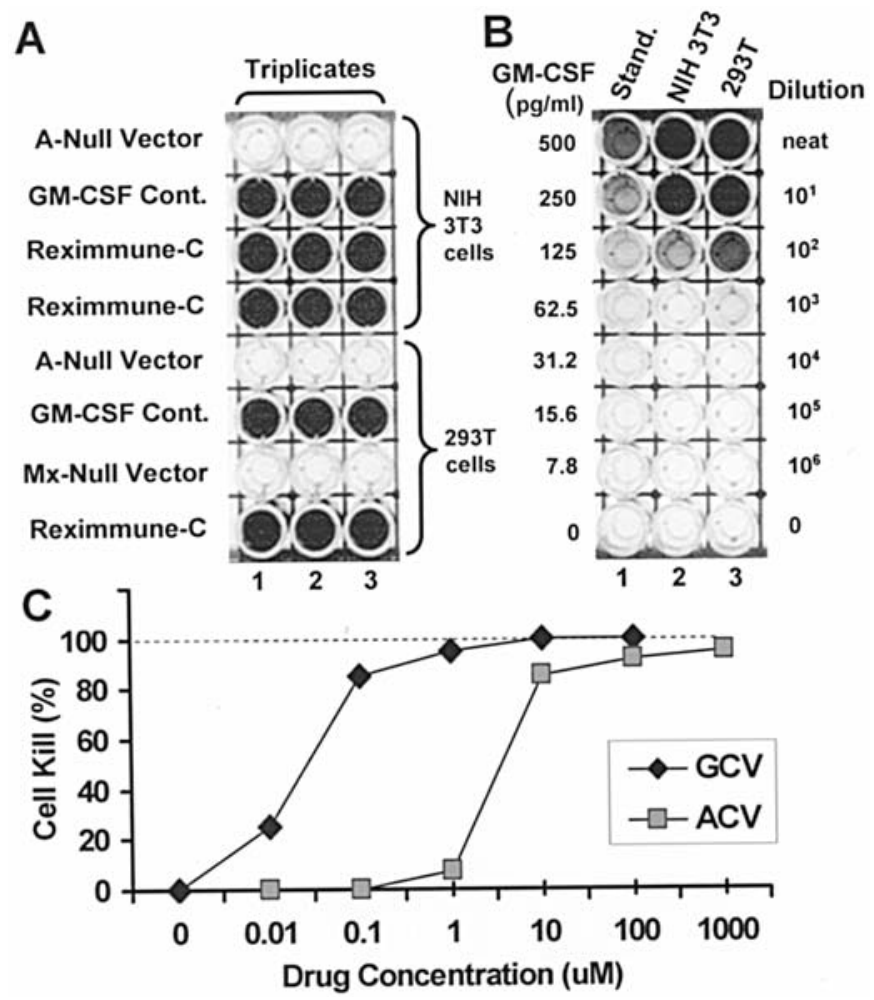

Figure 2. Characterization of Reximmune-C transgene expression in cultured cells. (A), The production and secretion of GM-CSF by Reximmune-C plasmids and its cognate retroviral vectors was evaluated by immunohistochemical staining of cultured cells using a polyclonal goat antibody raised against a peptide mapping at the amino terminus of human GM-CSF (Santa Cruz Biotechnology, Inc.). (B), GM-CSF production was measured by standardized ELISA (R\&D Systems, Inc.) in culture medium collected from both Reximmune-C vector-transduced NIH3T3 and plasmid-transfected 293T producer cell cultures. As shown here, GM-CSF secretion was $\sim 100 \mathrm{ng} / \mathrm{ml}$ in transfected $293 \mathrm{~T}$ cell cultures, $\sim 30 \mathrm{ng} / 10^{6}$ cells $/ \mathrm{ml}$ in vector-transduced NIH3T3 cell cultures. (C), The differential sensitivity of Reximmune-C-TNT vector transduced cells, bearing the auxiliary HSVtk gene, to the pro-drugs ganciclovir (GCV) and acyclovir (ACV) was validated by pharmacological studies in human A375 melanoma cells.

expression of human GM-CSF protein in resident cells ( 35\%) within the tumor xenografts of Reximmune-C vector-treated mice (Fig. $4 \mathrm{~B}$ and C), compared to $<1 \%$ in the non-targeted GM-CSF vector-treated and targeted null vector-treated mice (Fig. 4A). These findings demonstrate the feasibility of delivering cytokine genes to distant or inaccessible tumors by intravenous injection of pathotropically-targeted vectors such as Reximmune-C.

Further, extensive infiltration of host mononuclear cells was noted in the tumor nodules of Reximmune-C-treated mice (Fig. 5B and D) compared to minimal mononuclear infiltration observed with a non-targeted GM-CSF vector, a Mx-targetedbut-null vector-, or PBS-control treated animals (Fig. 5A and $\mathrm{C}$ ). Within the tumor xenografts, the tumor infiltrating lymphocyte (TIL) to tumor cell (T) ratio was as high as 20:1 in Reximmune-C-treated mice compared to 1:90 in non-targeted GM-CSF vector-treated mice, and 1:100 in Mx-targeted-butnull or PBS-treated animals. Immunohistochemical staining confirmed that the infiltrating host mononuclear cells include CD40+ (Fig. 6B) and CD86 ${ }^{+}$cells (Fig. 6D), thus identifying $\mathrm{B}$ cells and dendritic cells, respectively, among the tumor infiltrating lymphocytes. While athymic mice are deficient in 


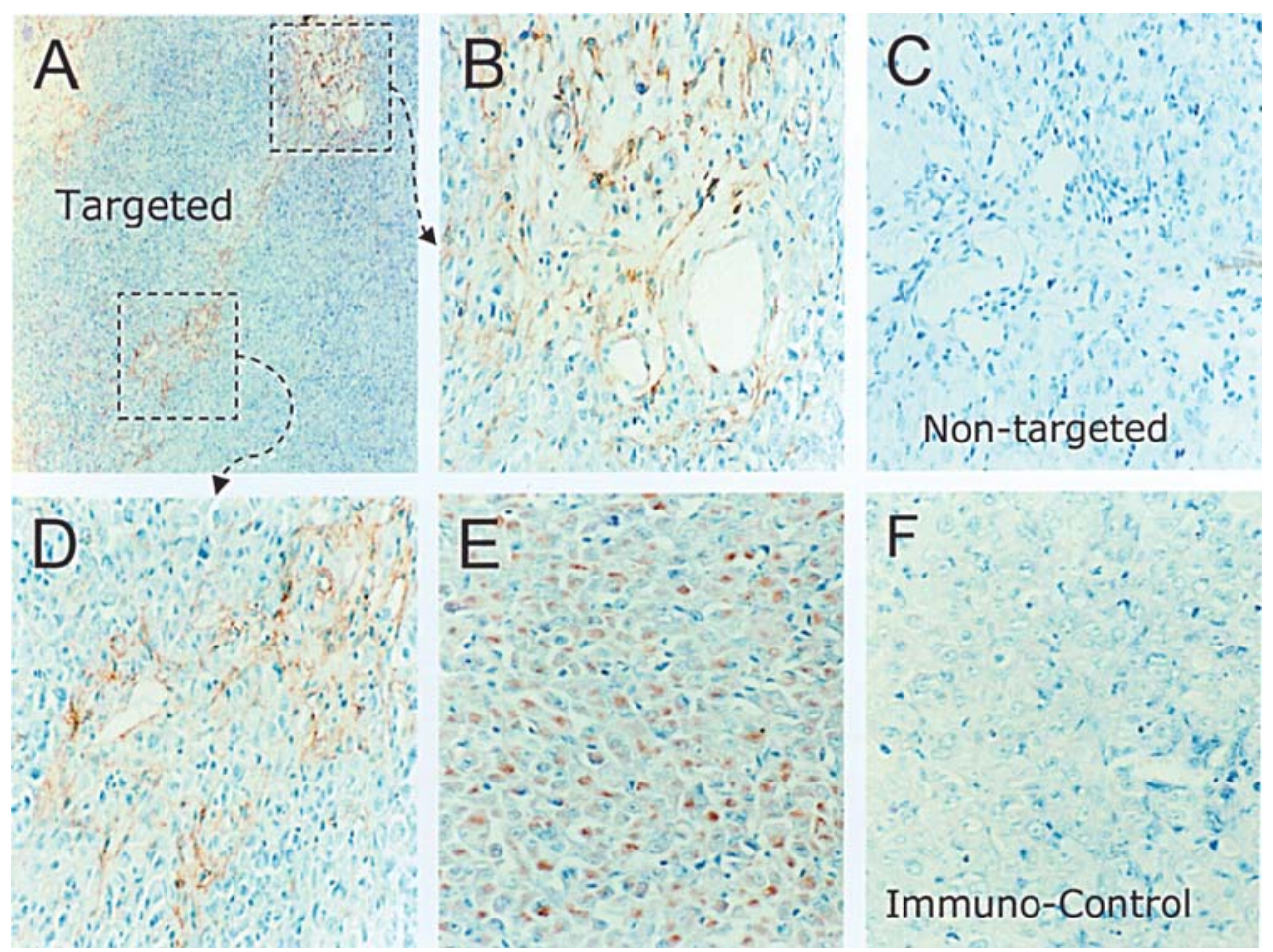

Figure 3. Biodistribution of pathotropic nanoparticles into metastatic lesions in nude mice. Preclinical models of metastatic pancreatic cancer, wherein human tumor xenografts of MiaPaca 2 cells were implanted into the flanks of athymic nude mice, provided a unique view of the penetrance and over-all efficiency of the tumor-targeted vectors. When retroviral vectors bearing a $\beta$-galactosidase marker gene are infused into the tail vein of tumor-bearing mice, these vectors traverse the heart and lungs and the heart again, only to leave the vascular system (A) and accumulate in the cancerous tissues (B and D) within 60 min of infusion (as determined by specific immunocytochemical staining), displaying a physiological surveillance function that is entirely dependent on the targeting domain (C). Spreading throughout the tumors like moisture in a sponge, the vectors selectively deliver their genetic payloads to proliferative tumor cells (E) with high efficiency. (F), represents an immunocytochemical control.

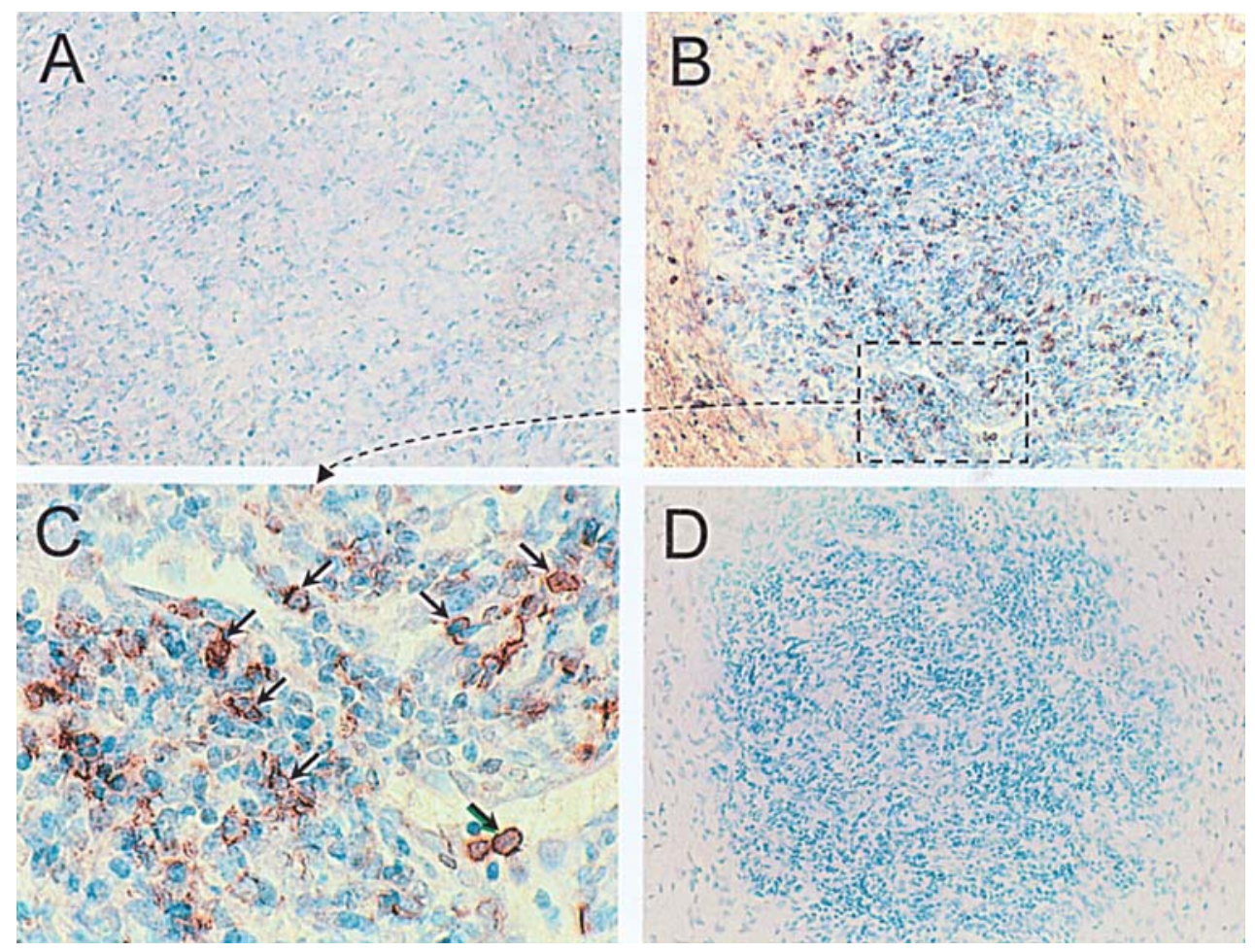

Figure 4. GM-CSF production in tumors of Reximmune-C vector-treated mice. Subcutaneous tumor xenografts were established in athymic nu/nu mice by subcutaneous implantation of $1 \times 10^{7}$ MiaPaca2 cells. When the tumors reached a size of $\sim 20 \mathrm{~mm}^{3}, 200 \mu 1$ of either the Reximmune-C vector (B-D) or a non-targetedGM-CSF control vector (A) was injected directly into the tail vein daily for 10 days (cumulative vector dose: $2 \times 10^{7} \mathrm{CFU}$ for each vector). The mice were sacrificed one day after completion of the treatment, and the harvested tumor sections were immunostained for presence of the GM-CSF transgene using a goat polyclonal anti-GM-CSF antibody. Immunoreactive GM-CSF protein was noted in $\sim 35 \%$ of cells throughout the tumor nodules of Reximmune-C vector-treated mice (B and C) compared to $<1 \%$ in the non-targeted CAE-GM-CSF vector-treated mice (A). (D), represents a Reximmune-C-treated nodule without primary antibody, which served as an immunocytochemical control. 

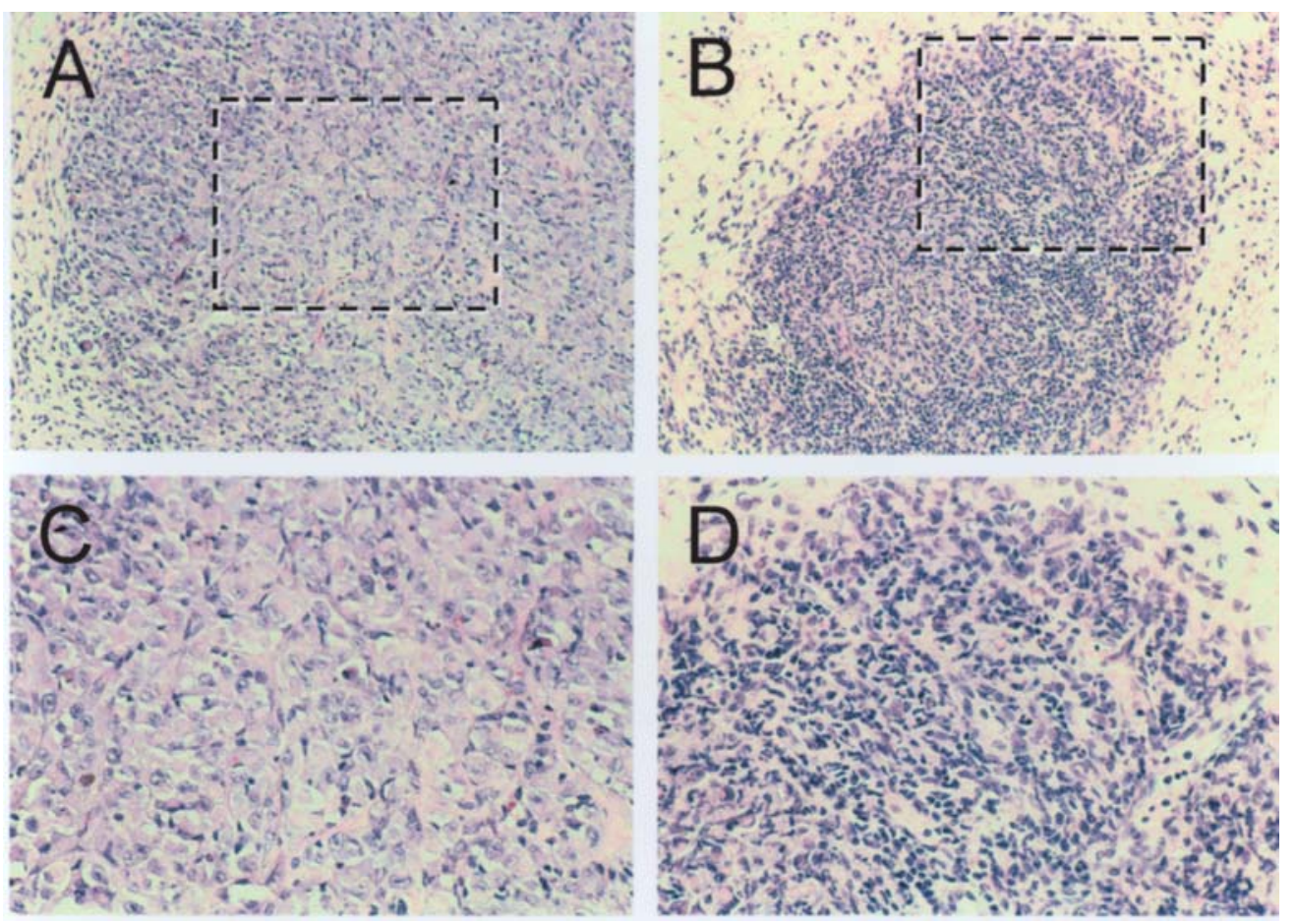

Figure 5. Cytokine-directed recruitment of host mononuclear cells into tumors of Reximmune-C-treated mice. This figure illustrates the recruitment of host mononuclear cells into the tumor nodule after repeated intravenous injections of Reximmune-C in tumor-bearing mice. Standard H\&E sections of a tumor nodule are shown: (A, C box at higher magnification): Null vector control showing baseline infiltration; (B, D box at higher magnification): Reximmune-C-treated animal showing massive immune infiltration into the tumor nodule.
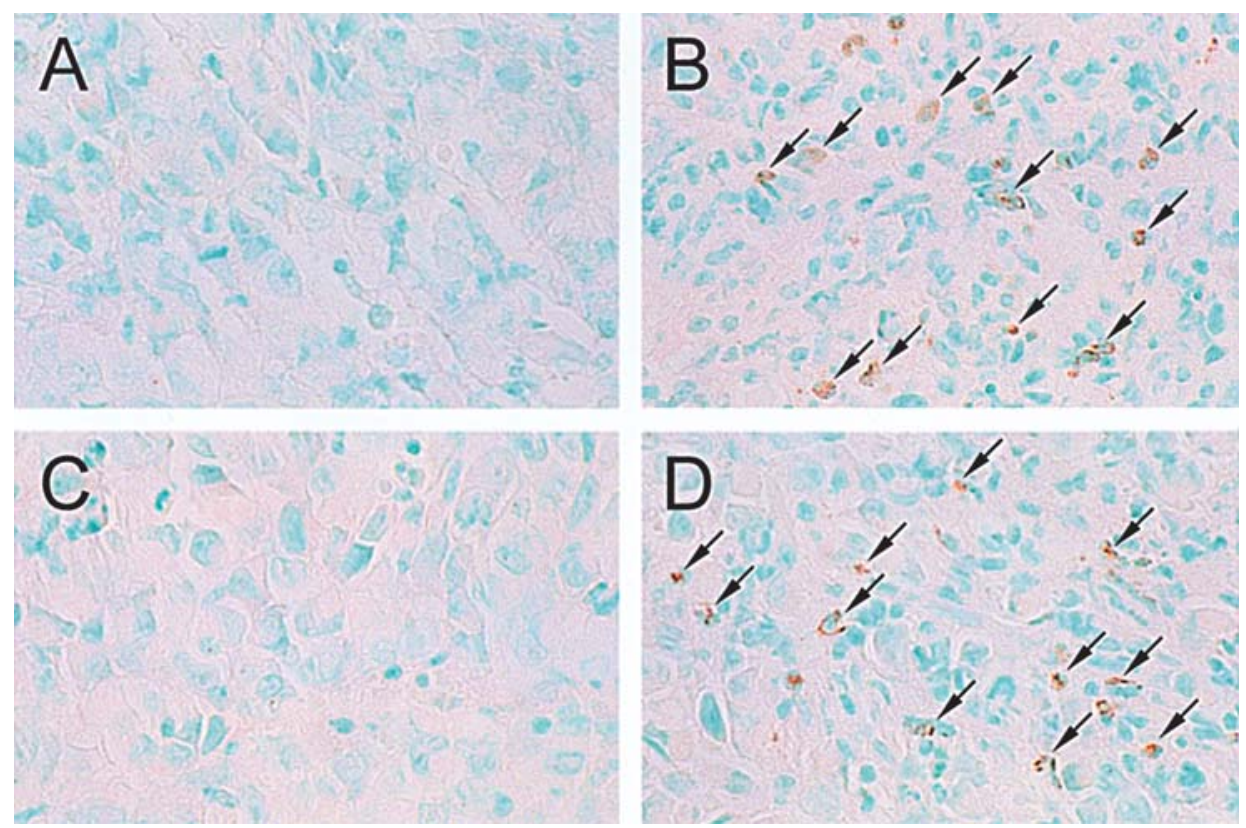

Figure 6. Identification of dendritic cells and B cells within the tumor nodules of Reximmune-C-treated mice. Immunohistochemical staining confirmed that the infiltrating host mononuclear cells observed in tumor sections of Reximmune-C-treated mice included both $\mathrm{CD} 40^{+}(\mathrm{B})$ and $\mathrm{CD} 86^{+}(\mathrm{D})$, thus identifying B cells and dendritic cells, respectively, as the tumor infiltrating lymphocytes. In contrast, immunohistochemical staining was negative for CD40 (A) and CD86 (C) antigens in mice treated with the non-targeted GM-CSF vector, thereby confirming that the recruitment of these tumor infiltrating lymphocytes is a result of the targeted delivery of the GM-CSF cytokine gene to the locus of the tumor nodule.

$\mathrm{T}$ cells, these findings indicate successful recruitment of available host antigen-presenting cells and humoral antibodyproducing $\mathrm{B}$ cells into the tumor nodules by the immunomodulatory action of the GM-CSF protein secreted by the very cancer cells targeted by Reximmune- $\mathrm{C}$ in this preclinical model of metastatic cancer.

Since the systemic administration of recombinant human GM-CSF protein at therapeutic levels can be associated 
with toxic systemic side effects, we measured the levels of human GM-CSF in the sera of mice treated with high-dose Reximmune-C for 10 days. Human GM-CSF was not detected $(<10 \mathrm{pg} / \mathrm{ml}$ detection limits) in sera of 4 mice treated with the highest dose of Reximmune-C, and serum chemistry levels and complete blood counts were within normal limits. These findings indicate that intravenous administration of Reximmune-C produces a localized expression of GM-CSF in effective local concentrations, and thus would not have the undesirable systemic toxicities that frequently limit the clinical utility of commercially available recombinant human GM-CSF.

Deployment of Reximmune-C in pilot clinical studies. With the approval of Rexin-G for clinical use in treating all solid tumors that are refractory to standard chemotherapy in the Philippines, came the possibility of examining the safety and potential efficacy of sequential targeted gene delivery in clinical cases of otherwise intractable cancer. Thus we began a Phase I Feasibility Study of sequential targeted gene delivery using both Rexin-G and Reximmune-C - two tumor-targeted gene delivery vectors designed to deliver its respective genetic payload to metastatic cancer cells. Rexin-G and Reximmune-C were prepared and delivered as separate pathotropic nanoparticles bearing a cytocidal cyclin G1 gene or a GM-CSF gene, respectively. As demonstrated in Fig. 3, when injected intravenously, these targeted vectors seek out and accumulate in cancerous lesions, thus increasing the effective local concentrations of the nanoparticles within the tumors.

The working hypothesis behind this two-stage approach to cancer management predicts that a strategic and individualized vaccination of a patient against his/her own cancer can be achieved by combining i) the targeted vector bearing a potent cytocidal construct, Rexin-G, with ii) a targeted vector bearing an immune activating gene, Reximmune- $\mathrm{C}$. The tumortargeted Rexin-G is given first to kill the cancer cells and thus expose neoantigens within the tumor nodules, followed by Reximmune-C to recruit the body's immune cells to the same cancer compartments, thereby prompting recognition of the tumor neoantigens in situ and thereby promoting a longlasting anti-tumor immunity. If successful, the strategy would be of considerable utility in cancer patients who have received clinical benefits from Rexin-G in the form of tumor control, but are still at risk of recurrence.

The purpose of the Phase I clinical study was to evaluate the overall safety/toxicity and therapeutic potential of this sequential regimen, using i.v. infusions of Rexin-G followed by pulses of Reximmune-C, in an effort to achieve a personalized cancer vaccination in vivo in patients with chemoresistant solid tumors. The initial results of the first seven cancer patients in the Phase I study were recently presented at a 2008 Meeting of the American Society of Clinical Oncology, (44) and a detailed report on the clinical data will be presented elsewhere (Cornelio et al, unpublished data). Meanwhile, we report herein on the biotechnological proofsof-principle that have been demonstrated to date. As shown in Fig. 7, sequential infusions of Rexin-G followed by Reximmune-C in a patient with metastatic non-small cell lung cancer (NSCLC) revealed extensive apoptosis and necrosis of cancer cells in the tumorous organ, and recruitment of significant amounts of immune infiltrates (Fig. 7A). Expression
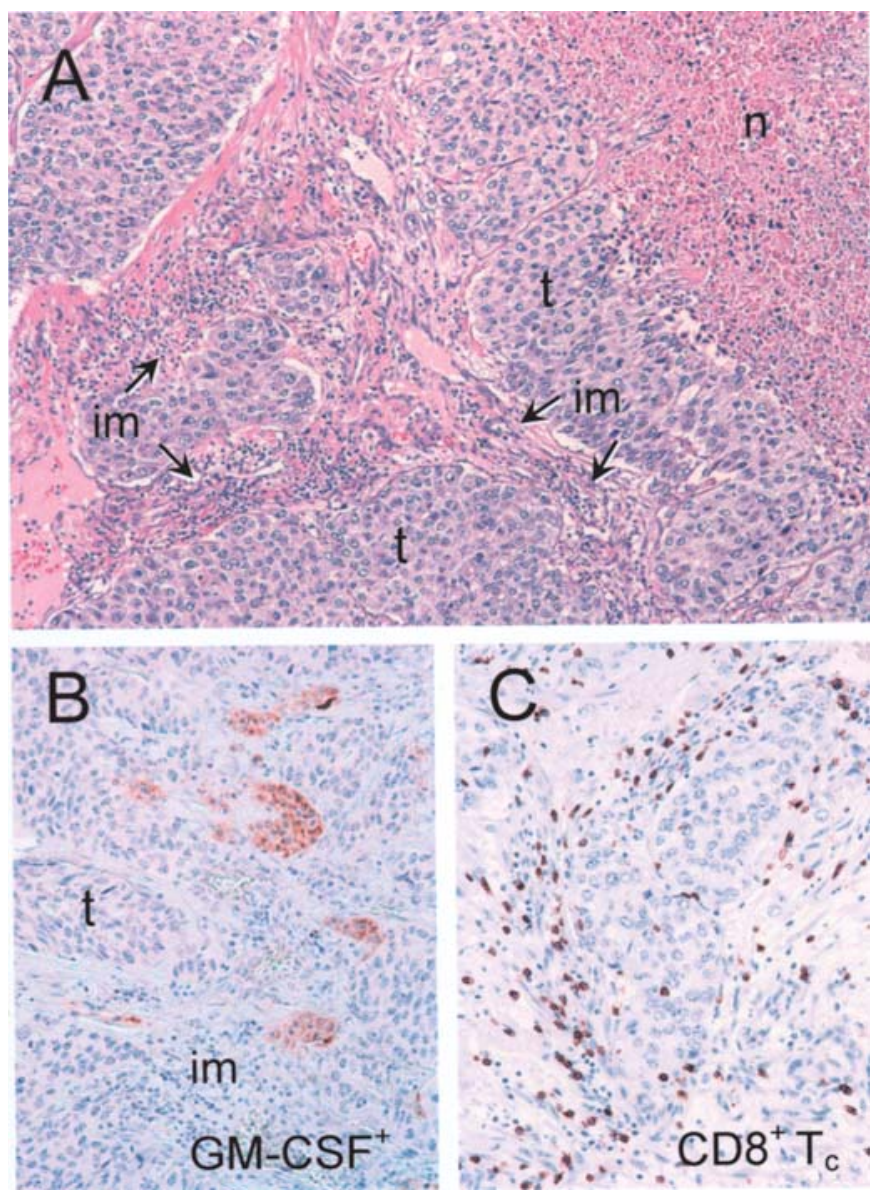

Figure 7. Validation of the cancer vaccination strategy in pilot clinical studies. Clinical application of Reximmune-C, administered in combination with Rexin-G, confirmed the major points addressed in the preclinical studies. (A), shows a H\&E-stained section of a surgically resected tumorous adrenal gland obtained following a sequential regimen of Rexin-G followed by Reximmune-C. Massive areas of necrosis (n) is observed throughout the tumor, presumably by the cytocidal action of Rexin-G; as are significant streams of immune infiltrates (im), apparently in response to a localized paracrine secretion of the cytokine transgene. (B), The production/secretion of the GM-CSF by the transduced cancer cells themselves was confirmed by the presence of small clusters of GM-CSF-expressing tumor cells in these same fields. (C), Among the complement of tumor infiltrating lymphocytes are a significant number of $\mathrm{CD}^{+}$killer $\mathrm{T}$ cells, seen here surrounding a cluster of flagrant tumor cells, indicating that personalized cancer vaccination via this approach is a realistic goal.

of the GM-CSF transgene by cancer cells within the tumorinfiltrated adrenal gland was confirmed by immunohistochemical staining of resected tumor sections (Fig. 7B), as was the presence of a host of tumor infiltrating lymphocytes (TILs), including CD68+ macrophages and CD8 ${ }^{+}$killer $\mathrm{T}$ cells (Fig. 7C). Importantly, GM-CSF protein was not detected in serum samples either during or after treatment with Reximmune-C, indicating that the immunostimulatory influence of GM-CSF transgene expression was limited and that the intended cancer vaccination was highly localized, as designed.

\section{Discussion}

Retroviral expression vectors display an array of virtues and limitations that make these gene delivery vehicles an ideal 
choice for prospective cancer gene therapy applications $(10,22)$. The modern vectors derived from the MoMLV vector core are largely 'stealth' in terms of rapid immune inactivation, thereby enabling repeated vector infusions over extended periods of time in an effort aimed at sustained tumor control (34-36). The progressive development of clinical grade vectors (Fig. 1) served to enhance this property of 'stealth' by transitioning to human producer cells $(19,20,37)$, while improving vector production, gene expression, and titers, and virtually eliminating concerns over inadvertent recombination events that might yield untoward RCR infectivity (41-43). A further limitation of this class of C-type retrovirus is the restriction of the therapeutic gene expression to actively dividing cells only, which serves to focus the functional gene delivery to proliferative cancer cells and their associated neovasculature, while sparing normal cells and tissues. This same set of virtues and intrinsic limitations is applicable to the strategic delivery of immunomodulatory cytokine genes to sites of metastatic cancer to achieve a personalized cancer vaccination.

The prospects of selective gene delivery to sites of metastatic cancer is both enabled and exemplified by the development of pathotropic targeting technologies embodied in Rexin-G $(29,30,32,33)$, and which have now been extended to the targeted cancer vaccine, Reximmune-C.

The major advantages of precise tumor-targeted gene delivery are two-fold: first, it provides a simple method (intravenous infusion) of delivering therapeutic genes efficiently to surgically inaccessible sites such as metastatic tumors (34-36). Second, the preferential vector accumulation and integration at specific tumor loci reduces the number of vector particles available for biodistribution to non-target organs, while limiting paracrine cytokine secretion to specific tumor sites would tend to minimize the incidence of systemic toxicity.

In this study, we describe the development, construction, characterization, preclinical evaluation, and clinical validation of Reximmune-C, a tumor-targeted retroviral vector designed to deliver GM-CSF selectively to sites of metastatic cancer for the purposes of anti-cancer vaccination. Evaluation of the expression and secretion of the GM-CSF transgene in various human cancer cells in vitro, provides an estimate of 50 ng/ $10^{6}$ cells $/ 24 \mathrm{~h}$ (which is well within the range of productivities reported for mammalian expression systems) which can be used as an approximation to predict the pharmacological productivity in vivo (see below). In a series of preclinical studies of metastatic cancer, the selectivity, tissue penetrance, and over-all efficiency of pathotropic tumor targeting was demonstrated (Fig. 3); the expression/secretion of GM-CSF transgene/protein within the remote tumor nodules was confirmed (Fig. 4); the subsequent recruitment of host mononuclear cells into tumor nodules was documented (Fig. 5); and characterization of the phenotype of the activated tumor infiltrating lymphocytes, which included professional antigenpresenting dendritic cells, was performed (Fig. 6). These predictable immunostimulatory influences of GM-CSF were all achieved at the local level, i.e., metastatic sites, while the circulating blood levels of GM-CSF in the Reximmune-Ctreated animals remained undetectable. Thus, the critical proofs-of-principle that validate the performance of the gene targeting system, the physiological effects of the cytokine, and the general safety of the approach all encourage clinical development of Reximmune-C for cancer immunotherapy.

Virtually all of the active principles established in preclinical studies were recently validated in the crucible of clinical medicine (44). In a Phase I safety study in which the tumoricidal Rexin-G was used to provide abundant tumor neoantigens, while the Reximmune-C was employed to deliver the GM-CSF bearing Reximmune-C, both the partial destruction of the tumors and the localized secretion of the immunostimulatory cytokine was confirmed, as was the recruitment of a significant amount of immune infiltrate. However, unlike the nude mouse, which lacks a complement of functional $\mathrm{T}$ cells, the tumorous adrenal gland of the patient with metastatic NSCLC was infiltrated by a spectrum of TILs which included $\mathrm{CD}^{+}$killer T cells (Fig. 7). Here again, the immunostimulatory effects were observable within the microenvironment of the metastatic tumor nodule, while the blood levels of GM-CSF remained basal.

At this point, several additional points-to-consider are worthy of discussion. First is the need to further ascertain the optimal sequence and timing of the vaccination pulse in relation to the presentation of neoantigens in the form of tumor debris, since there seems to be a significant difference in the type of anti-cancer immunity, cellular versus humoral, that is generated under these different scenarios $(3-5,8,9)$. And until such refinements can be integrated with certainty into the clinical protocols, one would continue to utilize a 'sandwich' approach in which Rexin-G is administered both before and after the vaccination pulse. The next point-toconsider concerns the recommended dosage of immunomodulatory Reximmune- $\mathrm{C}$, which is presumably far less than the doses of cytocidal Rexin-G needed to bring chemoresistant metastatic cancer under control (34-36). If we can make some tentative approximations from the preclinical and clinical data currently at hand, and the Calculus of Parity (performance coefficient of the targeting system) obtained from a variety of clinical cases (35), we can estimate a starting point of $\sim 1 \mathrm{ml}$ of Reximmune-C for future clinical protocols at a titer of $1 \times 10^{10} \mathrm{U} / \mathrm{ml}$, as follows:

$$
\mathrm{D}=\frac{\mathrm{P} \mathrm{T} \mathrm{IV}}{\Phi}
$$

where daily dose (D) in $\mu \mathrm{g} /$ day equals production $(\mathrm{P})$ in $\mathrm{ng} /$ $10^{6}$ cells $/ 24 \mathrm{~h}$ multiplied by vector titer $(\mathrm{T})$ in gene transfer units/ml, multiplied by infusion vol (Iv) in $\mathrm{ml}$, divided by the performance coefficient $(\Phi)$ in gene transfer units/cell. For example:

$$
\text { Dose }=\frac{50\left(\mathrm{ng} / 10^{6} \text { cells } / 24 \mathrm{~h}\right) \times 10^{10}(\mathrm{U} / \mathrm{ml}) \times 1(\mathrm{ml})}{100(\mathrm{U} / \text { cell })}
$$$$
=5 \mu \mathrm{g} / 24 \mathrm{~h}(\text { per } 1 \mathrm{ml} \text { of Reximmune-C vaccine })
$$

This dose of Reximmune-C, while shown to be effective at the level of the metastatic cancer nodule, is a fraction of the doses of GM-CSF that are generally given systemically as an adjuvant in cancer immunotherapy protocols, which ranges from $80 \mu \mathrm{g} /$ day for 4 consecutive days (45) to $125 \mu \mathrm{g} /$ day for 
14 consecutive days (46) to $250 \mu \mathrm{g} /$ day for 5 consecutive days (47).

In an effort to provide clinical oncologists with the most robust and advanced molecular genetic tools possible, further refinement of the Reximmune- $\mathrm{C}$ vector to include a 'fail-safe' or OFF switch, in terms of sensitivity to the herpetic prodrugs Ganciclovir or Acyclovir, was accomplished by the addition of the HSVtk gene to the GM-CSF expression cassette, thereby generating the Reximmune-C-TNT vector, which establishes a new state-of-the-art. The development of this new 'fail-safe' vector provides an unprecedented precision in terms of regulating cytokine expression by pharmacological means (i.e., limiting the number of days of cytokine production following GM-CSF transgene delivery), which will enable repeated personalized vaccinations to be given with a controllable margin of safety. Taken together, this new generation of retroviral vectors enables clinical applications that reach beyond the field of the most gifted surgeon, beyond the reach of the finest of catheters, to the very fabric of nature to bring about the control of metastatic disease and to encourage the patient's natural immune responses that work in concert with the clinician towards that end.

\section{Acknowledgements}

This paper is dedicated to those who are no longer present, yet in whose memory and honor we continue to strive. The authors are grateful to the clinical investigators of the Phase I/II study, Gerardo H. Cornelio, Conrado C. Lorenzo III, Francisco F. Lopez, and to Evangeline Camunayan, Antonette Balais, and Alicia B. De Guzman for technical assistance. This work was supported by Epeius Biotechnologies Corporation, San Marino, CA, USA.

\section{References}

1. Warren TL and Weiner GJ: Uses of granulocyte-macrophage colony-stimulating factor in vaccine development. Curr Opin Hematol 7: 168-173, 2000.

2. Kim JJ, Yang JS, Lee DJ, Nottingham LK, Morrison L, Tsai A, Oh J, Dang K, Dentchev T, Agadjanyan MG, Sin JL, Chalian AA and Weiner DB: Macrophage colony-stimulating factor can modulate immune responses and attract dendritic cells in vivo. Hum Gene Ther 11: 305-321, 2000.

3. Jaffee EM: Immunotherapy for cancer. Ann NY Acad Sci 886: 67-72, 1999.

4. Drannoff G: GM-CSF-based cancer vaccines. Immunol Rev 188: 147-154, 2002.

5. Eager R and Nemunaitis J: GM-CSF gene-transduced tumor vaccines. Mol Ther 12: 18-27, 2005.

6. Suh KW, Piantadosi S, Yazdi HA, Pardoll DM, Brem H and Choti MA: Treatment of liver metastases from colon carcinoma with autologous tumor vaccine expressing granulocyte-macrophage colony-stimulating factor. J Surg Oncol 72: 218-224, 1999.

7. Soiffer R, Hodi FS, Haluska F, Jung K, Gillessen S, Singer S, Tanabe K, Duda R, Mentzer S, Jaklitsch M, Bueno R, Clift S, Hardy S, Neuberg D, Mulligan R, Webb I, Mihm M and Dranoff G: Vaccination with irradiated, autologous melanoma cells engineered to secrete granulocyte-macrophage colonystimulating factor by adenoviral-mediated gene transfer augments antitumor immunity in patients with metastatic melanoma. J Clin Oncol 21: 3343-3350, 2003.

8. Mellstedt H, Fagerberg J, Frodin JE, Henriksson L, HjelmSkoog AL, Liljefors M, Ragnhammar P and Osterborg A: Augmentation of the immune response with granulocyte-macrophage colony-stimulating factor and other hematopoietic growth factors. Curr Opin Hematol 6: 169-175, 1999.
9. Nagai E, Ogawa T, Ikubo A and Suzuki T: Irradiated tumor cells adenovirally engineered to secrete granulocyte/macrophagecolony-stimulating factor establish antitumor immunity and eliminate pre-existing tumors in syngeneic mice. Cancer Immunol Immunother 47: 72-80, 1998.

10. Fong TC, Sauter SL, Ibanez CE, Sheridan PL and Jolly DJ: The use and development of retroviral vectors to deliver cytokine genes for cancer therapy. Crit Rev Ther Drug Carrier Syst 17: 1-60, 2000.

11. Borrello I, Sotomayor EM, Cooke S and Levitsky HI: A universal granulocyte macrophage colony-stimulating factor-producing bystander cell line for use in the formulation of autologous tumor cell-based vaccines. Hum Gene Ther 10: 1983-1991, 1999.

12. Tai K, Chen D and Hwang L: Curative potential of GM-CSFsecreting tumor cell vaccines on established orthotopic liver tumors: mechanisms for the superior antitumor activity of liver tumor cell vaccines. J Biomed Sci 11: 228-238, 2004.

13. Kurane S, Arca MT, Aruga A, Krinock RA, Krauss JC and Chang AE: Cytokines as an adjuvant to tumor vaccines: efficacy of local methods of delivery. Ann Surg Oncol 4: 579-585, 1997.

14. Dranoff G: Cytokines in cancer pathogenesis and cancer therapy. Nat Rev Cancer 4: 11-22, 2004.

15. Zhang Y and Chatterjee DK: Liposomes, dendrimers and other polymeric nanoparticles for targeted delivery of anticancer agents - a comparative study. In: Nanomaterials for Cancer Therapy. Kumar C (ed.) Wiley-VCH Verlag, pp338-370, 2006.

16. Waehler R, Russell SJ and Curiel DT: Engineering targeted viral vectors for gene therapy. Nat Rev Genet 8: 573-587, 2007.

17. Hitt MM and Gauldie J: Gene vectors for cytokine expression in vivo. Curr Pharm Des 6: 613-632, 2000.

18. Young LS, Searle PF, Onion D and Mautner V: Viral gene therapy strategies: from basic science to clinical application. J Pathol 208: 299-318, 2006.

19. Pensiero MN, Wysocki CA, Nader K and Kikuchi GE: Development of amphotropic retrovirus vectors resistant to inactivation by human serum. Hum Gene Ther 8: 1095-1101, 1996.

20. De Polo NJ, Harkleroad CE, Bodner M, Watt AT, Anderson CG, Greengard JS, Murthy KK, Dubensky TW Jr and Jolly DJ: The resistance of retroviral vectors produced from human cells to serum inactivation in vivo and in vitro is primate species dependent. J Virol 73: 6708-6714, 1999.

21. Miller DG, Adam MA and Miller AD: Gene transfer by retrovirus vectors occurs only in cells that are actively replicating at the time of infection. Mol Cell Biol 101: 4239-4242, 1990.

22. Gordon EM and Hall F: Nanotechnology blooms, at last (Review). Oncol Rep 13: 1003-1007, 2005.

23. Adamina M, Daetwiler S, Rosenthal R and Zajac P: Clinical application of recombinant virus-based cancer immunotherapy. Expert Opin Biol Ther 5: 1211-1224, 2005.

24. Verma IM and Weitzman MD: Gene therapy: twenty-first century medicine. Annu Rev Biochem 74: 711-738, 2005.

25. Yu SS, Han E, Hong Y, Lee JT, Kim S and Kim S: Construction of a retroviral vector production system with the minimum possibility of a homologous recombination. Gene Ther 10: 706-711, 2003.

26. Zhao Y, Zhu Y, Lee S, Li L, Chang E, Soong N-W, Douer D and Anderson WF: Identification of the block in targeted retroviral-mediated gene transfer. Proc Natl Acad Sci USA 96: 4005-4019, 1999.

27. Cosset FL, Morling FJ, Takeuchi U, Weiss RA, Collins MK and Russell SJ: Retroviral retargeting by envelopes expressing an N-terminal binding domain. J Virol 69: 6314-6322, 1995.

28. Peng K and Russell SJ: Viral vector targeting. Curr Opin Biotechnol 10: 454-457, 1999.

29. Hall FL, Gordon EM, Wu L, Zhu NL, Skotzko MJ, Starnes VA and Anderson WF: Targeting retroviral vectors to vascular lesions by genetic engineering of the MoMuLV gp70 envelope protein. Hum Gene Ther 8: 2183-2192, 1997.

30. Hall FL, Liu L, Zhu NL, Stapfer M, Anderson WF, Beart RW and Gordon EM: Molecular engineering of matrix-targeted retroviral vectors incorporating a surveillance function inherent in von Willebrand factor. Hum Gene Ther 11: 983-993, 2000.

31. Masood R, Gordon EM, Whitley MD, Wu BW, Cannon P, Evans L, Anderson WF, Gill P and Hall FL: Retroviral vectors bearing IgG-binding motifs for antibody-mediated targeting of vascular endothelial growth factor receptors. Int J Mol Med 8: 335-343, 2001. 
32. Gordon EM, Liu PX, Chen ZH, Liu L, Whitley MD, Gee C, Groshen S, Hinton DR, Beart RW and Hall FL: Inhibition of metastatic tumor growth in nude mice by portal vein infusions of matrix-targeted retroviral vectors bearing a cytocidal cyclin G1 construct. Cancer Res 60: 3343-3347, 2000.

33. Gordon EM, Liu PX, Chen ZH, Liu L, Whitley M, Liu L, Wei D, Groshen S, Hinton DR, Anderson WF, Beart RW and Hall FL: Systemic administration of a matrix-targeted retroviral vector is efficacious for cancer gene therapy in mice. Hum Gene Ther 12: 193-204, 2000.

34. Gordon EM, Cornelio GH, Lorenzo CC, Levy JP, Reed RA, Liu L and Hall FL: First clinical experience using a 'pathotropic' injectable retroviral vector (Rexin-G) as intervention for Stage IV pancreatic cancer. Int J Clin Oncol 24: 177-185, 2004.

35. Gordon EM, Lopez FF, Cornelio GH, Lorenzo CC III, Levy JP, Reed RA, Liu L, Bruckner HW and Hall FL: Pathotropic nanoparticles for cancer gene therapy. Rexin-G: three-year clinical experience. Int J Oncol 29: 1053-1064, 2006.

36. Gordon EM, Chan MT, Geraldino N, Lopez FF, Cornelio GH, Lorenzo CC III, Levy JP, Reed RA, Liu L and Hall FL: Le morte du tumour: histological features of tumor destruction in chemo-resistant cancers following intravenous infusions of pathotropic nanoparticles bearing therapeutic genes. Int J Oncol 30: 1297-1307, 2007.

37. Soneoka Y, Cannon PM, Ramsdale EE, Griffiths JC, Romano G, Kingsman SM and Kingsman AJ: A transient three-plasmid expression system for the production of high titer retroviral vectors. Nucleic Acids Res 23: 628-633, 1995.

38. Skotzko MJ, Wu LT, Anderson WF, Gordon EM and Hall FL: Retroviral vector-mediated gene transfer of antisense cyclin G1 (CYCG1) inhibits proliferation of human osteogenic sarcoma cells. Cancer Res 55: 5493-5498, 1995.

39. Fogolin MB, Eberhardt MO, Kratje R and Etcheverrigaray M: Choice of the adequate quantification method for recombinant human GM-CSF produced in different host systems. J Biotech 5: 243-250, 2002 .
40. Miller AD and Rosman GJ: Improved retroviral vectors for gene transfer and expression. Biotechniques 7: 984-986, 1989.

41. Kim SH, Yu SS, Park JS, Robbins PD, An CS and Kim S: Construction of retroviral vectors with improved safety, gene expression, and versatility. J Virol 72: 994-1004, 1998.

42. Yu SS, Kim JM and Kim S: High efficiency retroviral vectors that contain no viral coding sequences. Gene Ther 7: 797-804, 2000.

43. Lenz HJ, Anderson WF, Hall FL and Gordon EM: Clinical protocol: tumor site specific phase I evaluation of safety and efficacy of hepatic arterial infusion of a matrix-targeted retroviral vector bearing a dominant negative cyclin G1 construct as intervention for colorectal carcinoma metastatic to liver. Hum Gene Ther 10: 1515-1537, 2002.

44. Cornelio GH, Lorenzo CC, Lopez FF, Hall FL and Gordon EM: Phase I study of sequential targeted gene delivery: intravenous infusions of Rexin-G followed by Reximmune-C induce tumor necrosis and recruitment of tumor infiltrating lymphocytes in cancerous lesions. J Clin Oncol 26: 3077, 2008.

45. Ullenhag GJ, Frodin JE, Jeddi-Tehrani M, Strigard K, Eriksson E, Samanci A, Choudhury A, Nilsson B, Rossman ED, Mosolits S and Mellstedt H: Durable carcinoembryonic antigen (CEA)specific humoral and cellular immune responses in colorectal carcinoma patients vaccinated with recombinant CEA and granulocyte-macrophage colony-stimulating factor. Clin Cancer Res 15: 3273-3281, 2004.

46. Waller EK: The role of sargramostim (rhGM-CSF) as immunotherapy. Oncologist 12: 22-26, 2007.

47. Parmiani G, Castelli C, Pilla L, Santinami M, Colombo MP and Rivoltini L: Opposite immune function of GM-CSF administered as vaccine adjuvant in cancer patients. Ann Oncol 18: 226-232, 2007. 